\title{
Urinary free corticosteroid excretion and renal function
}

\author{
JUDITH GILLILAND AND P. J. PHILLIPS \\ From the Division of Clinical Chemistry, Institute of Medical and Veterinary Science, \\ Adelaide, South Australia 5000
}

SUMMARY Theoretically urinary free corticosteroid excretion should be affected by renal function and this would make it a less sensitive index of hypercortisolaemia. In 28 consecutive urine samples there was a clear relationship $(r=0.83 ; \mathrm{P}<0.001)$ over a range of creatinine clearances $0.3-200$ $\mathrm{ml} / \mathrm{min}$. Although an allowance could be made for renal function this would not necessarily improve the discrimination of normal from abnormal. Until data comparing corrected to uncorrected urinary free corticosteroid excretion become available, we recommend a short dexamethasone test as the initial investigation in patients with suspected hypercortisolaemia and abnormal plasma creatinine concentrations.

The assay of urinary free corticosteroid excretion UFC) is useful in the diagnosis of hypercortisolaemic states. It is a simple assay, which is specific for corticosteroids, integrates the plasma free corticosteroid concentration (P-F cort) over time, and is unaffected by changes of steroid turnover. It is sensitive because with hypercortisolaemia the P-F cort increases disproportionately (Burke and Beardwell, 1972). The principle of the test is simple:

\section{$\mathrm{UFC}=$ Amount filtered - Amount reabsorbed.}

Since the amount reabsorbed is a function of the amount filtered with P-F cort up to $8 \mu \mathrm{g} / \mathrm{dl}$ (222 $\mathrm{nmol} / \mathrm{l}$ ) (Lindholm, 1973; Sederberg-Olsen et al., 1975)

$$
\begin{aligned}
& \text { UFC }=\mathrm{K} \times \text { Amount filtered }+ \text { Constant } \\
& \text { and Amount filtered }=\text { GFR } \times \text { P-F cort } \\
& \text { UFC }=\mathrm{K} \times \text { GFR } \times \text { P-F cort }+ \text { constant }
\end{aligned}
$$

This relationship is compatible with data showing the dependence of UFC on P-F cort (Hsu and Bledsoe, 1970; Burke and Beardwell, 1972; Sederberg-Olsen et al., 1975) and of free cortisol clearance on creatinine clearance (Burke and Beardwell, 1973). It would predict a decreased UFC with impaired renal function, which would make UFC a less sensitive index of hypercortisolaemia. We therefore studied the effect of renal function on UFC.

\section{Methods}

Twenty-eight consecutive urine samples submitted to the Institute of Medical and Veterinary Science for creatinine clearance ( $\mathrm{C}$ creat) were assayed for UFC by a modification of the method of Hsu and Bledsoe (1970) using QAE Sephadex to separate the bound steroid. The relationship of UFC and C creat was determined by linear regression analysis.

\section{Results and discussion}

There was a clear relationship between UFC and C creat $(\mathrm{r}=0.83 ; \mathrm{P}<0.001)$ over the range studied (0.3-200 ml/min) (Figure). Thus a P-F cort which would produce an abnormal UFC with normal renal function might produce a normal UFC with impaired renal function. This could easily occur since approximately half the patients with proved hypercortisolaemia have UFC less than twice the highest normal value (Hsu and Bledșoe, 1970; Burke and Beardwell, 1972), and in some series overlap occurs (Beardwell et al., 1968). It is possible that separation of the two groups would increase if some allowance were made for renal function (for example, correcting to a standard $\mathrm{C}$ creat). This would remove the variance associated with variable renal function but would substitute the variance of creatinine clearance determination. The respective variances are not known, and the net effect of such a correction cannot be accurately predicted. Until data comparing corrected and uncorrected UFC become available, we 


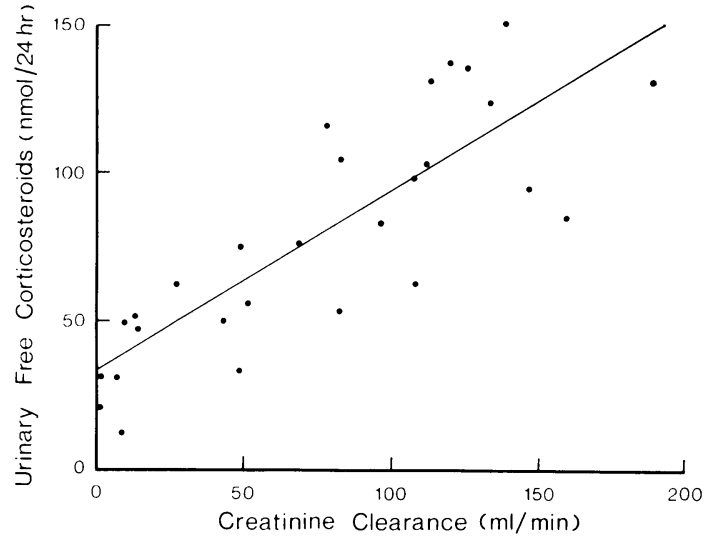

Figure Effect of renal function on urinary free corticosteroid excretion

$\mathrm{y}=0.60 x+32.8$

$\mathrm{r}=0.83 ; \mathrm{P}<0.001$

Conversion factor (SI to traditional units) -

Urinary free corticosteroid excretion: $1 \mathrm{nmol} \simeq 0.36 \mu \mathrm{g}$.

advise caution in interpreting UFC from patients with abnormal plasma creatinine concentrations and recommend a short dexamethasone suppression test.

We thank the staff of the Renal Unit of the Royal Adelaide Hospital for their enthusiastic co-operation.

\section{References}

Beardwell, C. G., Burke, C. W., and Cope, C. L. (1968). Urinary free cortisol measured by competitive protein binding. Journal of Endocrinology, 47, 79-89.

Burke, C. W., and Beardwell, C. G. (1972). Urinary free 흐 cortisol and compound $\mathrm{S}$ in the diagnosis of Cushing's syndrome. In Cushing's Syndrome-Diagnosis and $\mathbb{\varnothing}$ Treatment, edited by C. Binder and P. E. Hall, pp. 53-70. Heinemann, London.

Burke, C. W., and Beardwell, C. G. (1973). Cushing's $\vec{O}$ syndrome. An evaluation of the clinical usefulness of urinary free cortisol and other urinary steroid measure- $\vec{\omega}$ ments in diagnosis. Quarterly Journal of Medicine, 42, 175-204.

Hsu, T. H., and Bledsoe, T. (1970). Measurement of $\dot{\omega}$ urinary free corticoids by competitive protein-binding radioassay in hypoadrenal states. Journal of Clinical oे Endocrinology, 30, 443-448.

Lindholm, J. (1973). The renal excretion of cortisol. Scandinavian Journal of Clinical and Laboratory Investigation, 31, 115-118.

Sederberg-Olsen, P., Binder, C., and Kehlet, H. (1975). Urinary excretion of free cortisol in impaired renal function. Acta Endocrinologica, 78, 86-90.

Requests for reprints to: Dr P. J. Phillips, Division of Clinical Chemistry, Institute of Medical and Veterinary Science, Box 14, Rundle Street PO, Adelaide, South Australia 5000 . 